\title{
Milky Mangrove Excoecaria agallocha L. Plant as a source for potential mosquito larvicides
}

\author{
P. Pradeepa ${ }^{1 \dagger}$, K.Subalakshmi ${ }^{1 \dagger}$, A. Saranya ${ }^{2,}$ P. Dinesh ${ }^{2}$, Vinoth Arul Raj ${ }^{1}$, T. Ramanathan ${ }^{2} *$ \\ ${ }^{1}$ Arunai Engineering College, Thiruvannamalai, Tamilnadu, India. \\ ${ }^{2}$ Centre of Advanced Study in Marine Biology, Faculty of Marine Sciences, Annamalai University, Parangipettai, Tamilnadu, India.
}

\begin{tabular}{l} 
ARTICLE INFO \\
\hline Article history: \\
Received on: 07/01/2015 \\
Revised on: 06/02/2015 \\
Accepted on: 04/03/2015 \\
Available online:28/03/2015 \\
\hline Key words: \\
Mangroves, Excoecaria \\
agallocha, Aedes aegypti, \\
Culex quinquefasciatus, \\
Larvicidal activity. \\
\hline
\end{tabular}

\section{INTRODUCTION}

Mosquitoes are medically important arthropod vectors transmitting many diseases like Malaria, Encephalitis, Dengue fever, Yellow fever, filariasis, schistosomiasis, Chikungunya and Japanese encephalitis (Das and Ansari, 2003; Kamaraj et al., 2011; Tennyson et al., 2012). Larviciding is a successful way of reducing mosquito densities in their breeding places before they emerge into adults (Tiwary et al., 2007). Synthetic chemical insecticides such as organochlorine, organophosphorus, carbamates, pyrethrins and pyrethroids are currently used for larviciding purposes (Tiwary et al., 2007; Ali et al., 2013). However, their indiscriminate use resulted in several problems such as environmental pollution, insecticide resistance and toxic, hazardous which affect human health and disrupt the ecosystem (Devine, 2007; Bansal et al., 2011). Plants may be alternative sources of mosquito control agents (Hedlin et al., 1997). The investigation of insecticidal properties of plant-derived extracts concluded that they are environmentally safe, degradable, and

\footnotetext{
* Corresponding Author

Email: drtramanathan@gmail.com.

$\dagger$ These authors contributed equally to the work.
}

target specific (Senthil Nathan and Kalaivani,2005). Excoecaria agallocha (Figure 1) (Family: Euphorbiaceae) is a medicinal mangrove plant found in many tropical countries including India, Myanmar, Malaysia, Indonesia, Thailand, Philippines and Sri Lanka (Jayaweera,1980). It is commonly known as Thillai in Tamil and milky mangrove in English. The milky sap of this tree can cause temporary blindness if it enters the eyes (Vadlapudi et al., 2009). This plant has traditionally been used as purgative and in treatment of epilepsy, dermatitis, leprosy, toothache (Ramanathan, 2000). The potential medicinal value of this plant has been reported for antinociceptive, gastroprotective, antimicrobial, antioxidant, antihyperglycemic and anticancer properties (Simlai and Roy, 2013). The extract of various plant parts of the mangrove Excoecaria agallocha has been proved as a potential source of a mosquito larvicidal agent (Thangam and Kathiresan,1996, Thirunavukkarasu et al., 2011, Satyan et al., 2012). With this background, the present study assessed the role of mosquitoe larvicidal activities of hexane, chloroform, ethyl acetate, acetone, and methanol leaf extracts of Excoecaria agallocha leaves against the fourth instar larvae of Aedes aegypti and Culex quinquefasciatus. 


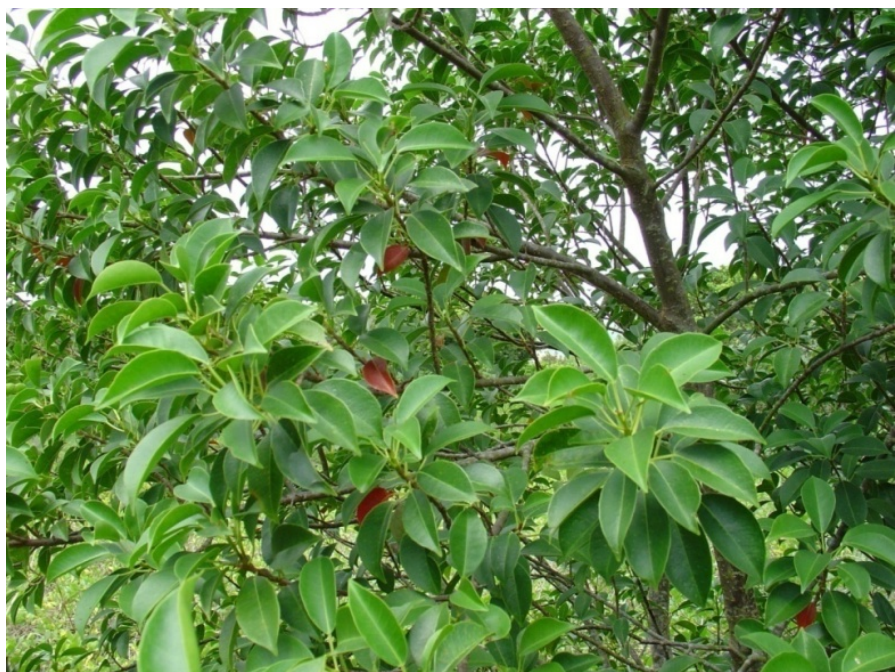

Fig. 1: Mangrove Plant - Excoecaria agallocha Linn.

\section{MATERIALS AND METHODS}

\section{Collection of plant materials}

The matured leaves of Excoecaria agallocha were collected from Parangipettai, Tamil Nadu in the month of January 2014. The collected plants were taxonomically identified and the leaves were carefully examined. Old, insect damaged and fungus infected leaves were removed. Healthy leaves were washed with dechlorinated water and spread out.

\section{Preparation of plant extracts:}

The collected leaves were shade dried for 7-10 days under room temperature $\left(27-37{ }^{\circ} \mathrm{C}\right)$ (Figure 2). The dried leaves were powdered mechanically using commercial electrical stainless steel blender (Figure 3). One kilogram dried powder was extracted by using five different solvents namely aqueous, Methanol, Acetone, Chloroform, Hexane individually based on increasing polarity by cold percolation (Figure 4). The extracts were filtered through a Buchner funnel with Whatman number 1 filter paper. The extract was then subjected to evaporation until solvents were completely evaporated to get the solidified crude extracts. The crude extracts thus obtained was stored and maintained at $4{ }^{\circ} \mathrm{C}$ in a refrigerator.

\section{Mosquito culture:}

The Aedes aegypti and Culex quinquefasciatus mosquito larvae (Figure 5) were collected from stagnant water areas of Parangipettai coastal environment, Tamil Nadu. The larvae were maintained at $25-27^{\circ} \mathrm{C}, 75-85 \%$ relative humidity under $14: 10$ light and dark photo period cycle. They fed with a mixture of dog biscuits and yeast powder (3:1) and the water in the tray was changed daily (Kamaraj et al., 2009).

\section{Larvicidal bioassay}

Mosquito larvicidal activity of various solvent extracts of Excoecaria agallocha leaves was assessed at varying grades of concentration such as 20,40,60,80, $100 \mathrm{mg} / \mathrm{ml}$ of Tween 80 and the samples were diluted with $99 \mathrm{ml}$ of distilled water. Standard
World Health Organization protocol (World Health Organization, 1996) was employed with modification for the bioassay procedure. Ten larvae of same stage (i.e. $4^{\text {th }}$ instar) were put into beakers containing the test solution of each above mentioned concentration. Distilled water $(99 \mathrm{ml})$ containing Tween $80(1 \mathrm{ml})$ was used as control. For each concentration and control, three replicates were used and each test was repeated three times. Observation on larval mortality was recorded after $24 \mathrm{hrs}$. Larvae were considered dead, when they failed to move after probing with a needle/brush. The number of dead larvae in each vial was counted and the percent mortality of larvae was calculated using the Abbott's formula (Abbott, 1925).

$\%$ corrected percentage $=1-\quad \mathrm{n}$ in test after treatment $\mathrm{X} 100$ $\mathrm{n}$ in control after treatment

\section{RESULTS AND DISCUSSION}

The marine environment is incomparable reservoirs of bioactive natural products, many of which exhibit structural features that have not been found in terrestrial natural products (Ali et al., 2013). Mangroves are biochemically unique vegetation that produce wide array of natural products with immense medicinal potential (Patra and Mohanta, 2014). They have natural metabolites with diverse biological activities such as antibacterial, antiviral activity, antidiarrhoeal, antifeedant activity, insecticidal activity and cytotoxic activity (Manilal et al., 2009). In this context, mangroves have received much attention as potentially useful natural larvicides (Thangam and Kathiresan,1988; Thangam and Kathiresan,1988(a); Thangam and Kathiresan,1989; Renugadevi et al., 2012). Crude hexane extract from the dried roots of E. agallocha inhibited $50 \%$ of the growth of third instar larvae of Culex quinquefasciatus within $24 \mathrm{~h}\left(\mathrm{LC}_{50}: 315 \mathrm{ppm}\right)$ (Satyan et al., 2012).

The highest mortality was found in Methanol and aqueous extract of mangrove plant extracts of Excoecaria agallocha bark against the larvae of Anopheles stephensi $\left(\mathrm{LC}_{50}\right.$ $=12.69,11.35$, and $\left.\mathrm{LC}_{90}=38.33,36.42\right)$, C. quinquefasciatus $\left(\mathrm{LC}_{50}\right.$ $=10.45,09.98$ and $\left.\mathrm{LC}_{90}=37.85,35.67\right)$, Aedes aegypti $\left(\mathrm{LC}_{50}\right.$ 14.87, 12.67 and $\mathrm{LC}_{90} 40.67,41.25$ ) (Thirunavukkarasu et al., 2011). The studies on mosquito larvicidal activities of leaf extracts of Excoecaria agallocha are too restricted. Hence, the present study was investigated the larvicidal action of various solvent extracts of the mangrove plant Excoecaria agallocha.

The larvicidal studies of Excoecaria agallocha leaf extracts have been tested among two species of mosquito larvae (i.e) Aedes aegypti and Culex quinquefasciatus. The percentage of mortality was calculated by using Abbott's formula. Controls did not reveal the effect on larvae. No mortality was observed in the control group of the experiment. The figures $6 \& 7$ will step out the mortality rate of both the species arrived at the end of $24 \mathrm{hrs}$ and they are tabulated based on their increasing polarity. A dose dependent lethality was observed in all the extracts. Methanol and hexane extracts showed the best mortality rate $(100 \%)$ against the larvae of Aedes aegypti and Culex quinquefasciatus. 


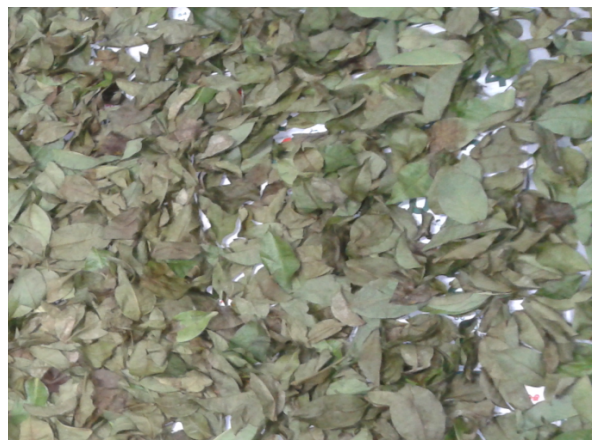

Fig. 2: Shade dried leaves.

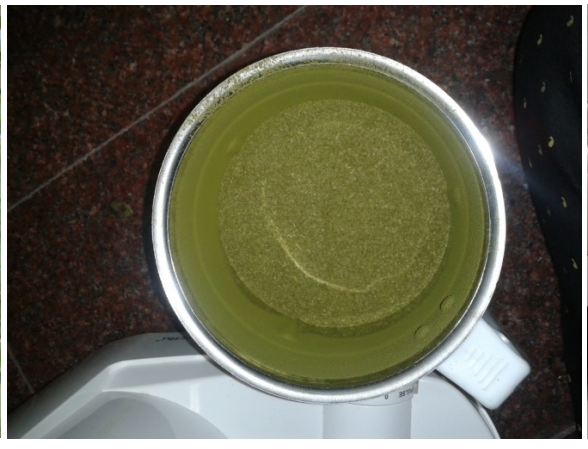

Fig. 3: Powdered sample.

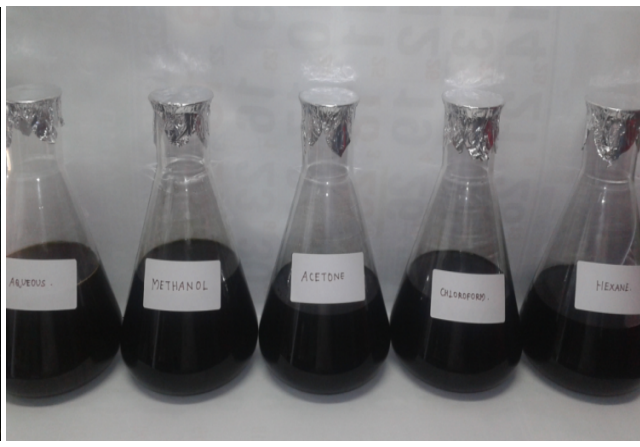

Fig. 4: Extraction with five different solvents.

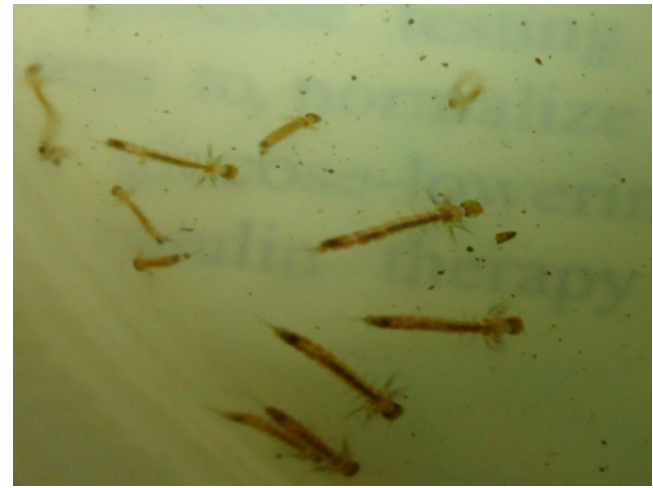

Fig. 5: Collected larvae.

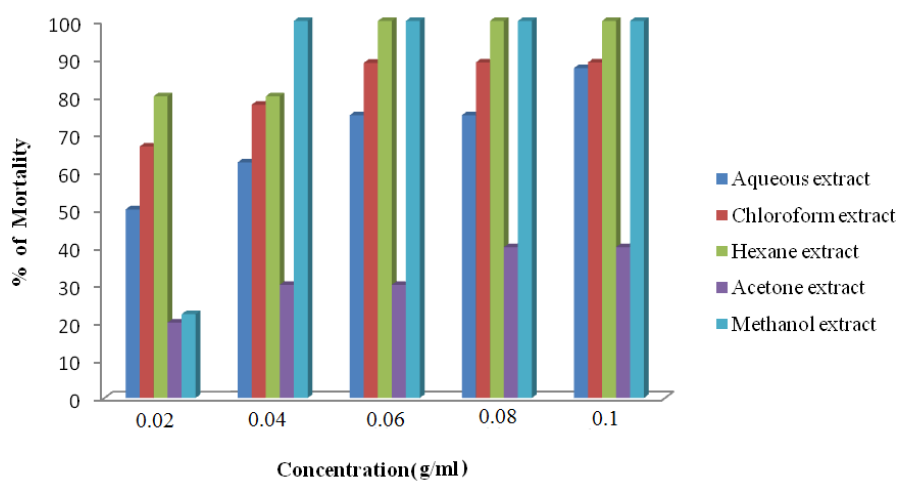

Fig. 6: Percentage mortality of Aedes aegypti treated with the various solvent extracts of Excoecaria agallocha leaves.

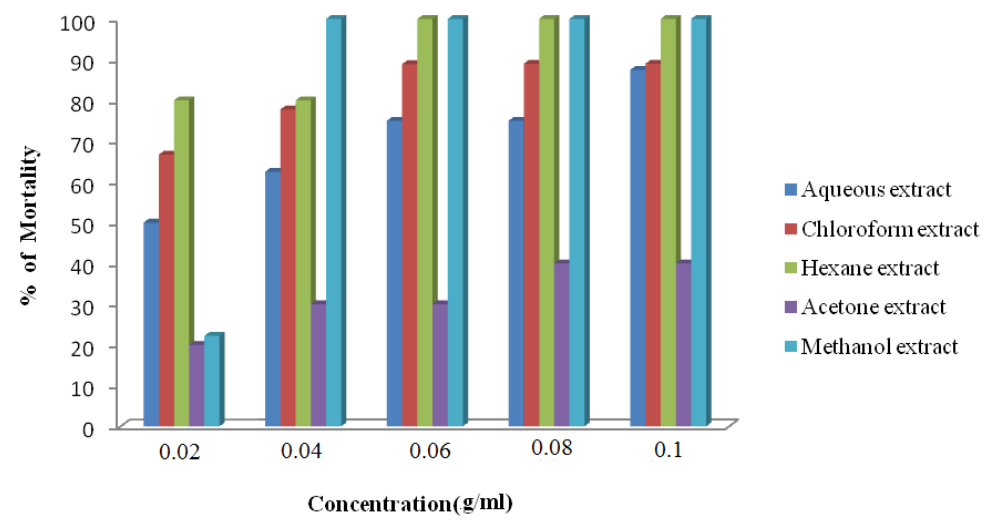

Fig. 7: Percentage mortality of Culex quinquefasciatus treated with the various solvent extracts of Excoecaria agallocha leaves.

Based on the mortality values, the potency of crude mangrove leaves extracts could be categorized as: Methanol> Hexane>chloroform > Aqueous > Acetone in the decreasing order.

In the present study, the higher percentage of mortality caused by the extracts is assumed to be caused by the active ingredients present in them. Further investigations are needed to elucidate the active ingredients of the extract responsible for larvicidal activity should be identified for field application of mosquito control.

\section{CONCLUSION}

It is concluded from the present study that methanol and hexane extracts of Excoecaria agallocha Linn. exhibited high mosquitoe larvicidal activities. Based on the earlier reports and the result of the present investigation, separation of active principles from Excoecaria agallocha Linn and studying their mode of action warrants further research for developing potent larvicidal compounds. 
These results could be useful in the search for novel, ecofriendly larvicide for the control of Aedes aegypti and Culex quinquefasciatus. It may help in reducing the environmental side effects by the synthetic insecticides.

\section{REFERENCES}

Abbott WS. A method of computing the effectiveness of an insecticide. J Econ Entomol, 1925; 18: 265-7.

Ali MYS, Ravikumar S, Beula JM. Mosquito larvicidal activity of seaweeds extracts against Anopheles stephensi, Aedes aegypti and Culex quinquefasciatus. Asian Pac J Trop Dis, 2013; 3(3): 196-201.

Aseer Manilal, S. Sujith, G. Seghal Kiran, Joseph Selvin and Chippu Shakir. Biopotentials of Mangroves Collected from the Southwest Coast of India. Global Journal of Biotechnology \& Biochemistry, 2009; 4 (1): 59-65.

Bansal SK, Singh KV, Sharma S, Sherwani MR. Comparative larvicidal potential of different plant parts of Withania somnifera against vector mosquitoes in the semi-arid region of Rajasthan. Journal of environmental biology / Academy of Environmental Biology, 2011; 32(1): $71-5$.

Das MK, Ansari MA. Evaluation of repellent action of Cymbopogan martinii martinii Stapf var sofia oil against Anopheles sundaicus in tribal villages of Car Nicobar Island, Andaman \& Nicobar Islands, India. Journal of vector borne diseases, 2003;40(3-4): 100-4.

Devine GJ, Furlong MJ. Insecticide use: Contexts and ecological successions. Agric Hum Values, 2007; 24: 281-306.

Hedlin PA, Holingworth RM, Masler EP, Miyamoto J, Thopson DG. 1997. Eds. Phytochemicals for pest control. ACS Symp Ser No. 658. Washington DC: American Chemical Society. p. 372.

Jayaweera DMA. Medicinal plants used in Ceylon. J Natl Sci Coun, 1980; 2: 214-215.

Kamaraj C, Bagavan A, Elango G, Zahir AA, Rajakumar G, Marimuthu S. Larvicidal activity of medicinal plant extracts against Anopheles subpictus \& Culex tritaeniorhynchus. The Indian journal of medical research, 2011; 134: 101-6.

Kamaraj C, Bagavan A, Rahuman AA, Zahir AA, Elango G, Pandiyan G. Larvicidal potential of medicinal plant extracts against Anopheles subpictus Grassi and Culex tritaeniorhynchus Giles (Diptera: Culicidae). Parasitology research. 2009; 104(5): 1163-71.

Mohamed Yacoob Syed Ali, Sundaram Ravikumar, Johanson Margaret Beula. Mosquito larvicidal activity of seaweeds extracts against Anopheles stephensi, Aedes aegypti and Culex quinquefasciatus. Asian Pac J Trop Dis, 2013; 3(3): 196-201.

Patra JK, Mohanta YK. Antimicrobial compounds from mangrove plants: A pharmaceutical prospective. Chinese journal of integrative medicine, 2014.

Ramanathan, T. 2000. Studies on Medicinal Plants of Parangipettai Coast (South East Coast of India). Ph.D. thesis, Annamalai University, Parangipettai, India. pp: 181.

Renugadevi G, Ramanathan $\mathrm{T}$, Shanmuga priya $\mathrm{R}$, Thirunavukkarasu P. Studies on Combined Effect of Mangrove Plants against Three Dangerous Mosquitoes. International. Journal of Pharmaceutical \& Biological Archives, 2012; 3(2): 357-62.
Samuel Tennyson, John Ravindran K, Arivoli S. Screening of twenty five plant extracts for larvicidal activity against Culex quinquefasciatus Say (Diptera: Culicidae). Asian Pacific Journal of Tropical Biomedicine, 2012; S1130-S1134.

Satyan RS, Sakthivadivel M, Shankar S, Dinesh MG. Mosquito larvicidal activity of linear alkane hydrocarbons from Excoecaria agallocha L. against Culex quinquefasciatus Say. Natural product research, 2012; 26(23): 2232-4.

Senthil Nathan S. Kalaivani K. Efficacy of nucleopolyhedrovirus (NPV) and azadirachtin on Spodoptera litura Fabricius (Lepidoptera: Noctuidae). Biol. Control. 2005; 34, 93-98.

Simlai A, Roy A. Biological activities and chemical constituents of some mangrove species from Sundarban estuary: An overview. Pharmacognosy reviews, 2013; 7(14): 170-8.

Subramonia thangam T, Kathiresan K. 1996. Marine plants for mosquito control. K.B. Wildey (editor). Proceedings of the Second International Conference on Urban Pests.

Thangam TS, Kathiresan K. Larvicidal effect of marine plant extracts on mosquito Culex tritaeniorhynchus. J Mar Bio Ass India, 1989; 31: 306-7.

Thangam TS, Kathiresan K. Toxic effect of mangrove plant extracts on mosquito larvae. Anopheles stephensi L Curr Sci 1988; 57 914-5.

Thangam TS, Kathiresan K. Toxic effect of seaweed extracts on mosquito larvae. The Indian journal of medical research, 1988 (a); 88: 357.

Thirunavukkarasu P, Ramanathan T, Renugadevi G, Jayalakshmi S. Studies on the larvicidal potential of Excoecaria agallocha L. bark extract. Journal of Pharmacy Research, 2011; 4(10): 3480.

Tiwary M, Naik SN, Tewary DK, Mittal PK, Yadav S. Chemical composition and larvicidal activities of the essential oil of Zanthoxylum armatum DC (Rutaceae) against three mosquito vectors. Journal of vector borne diseases, 2007; 44(3): 198-204.

Varahalarao Vadlapudi,Varaprasad Bobbarala, Somasekhar Penumajji, K. Chandrasekhar Naidu. Excoecaria agallocha $L$. Antimicrobial properties against important pathogenic microorganisms. International Journal of ChemTech Research, 2009; 1(4): 865-867.

World Health Organization. 1996. Report of the WHO informal consultation on the evaluation on the testing of insecticides, CTD/WHO PES/IC/96.1. Geneva: WHO. p. 69.

\section{How to cite this article:}

P. Pradeepa, K. Subalakshmi, A. Saranya P. Dinesh, Vinoth Arul Raj, T. Ramanathan. Milky Mangrove Excoecaria agallocha L. Plant as a source for potential mosquito larvicides. J App Pharm Sci, 2015; 5 (03): 102-105. 